\title{
An original approach of maxillary transversal deficiency with lingual orthodontics
}

\author{
C. Bernard-Granger ${ }^{1}$, R. Filippi ${ }^{1}$, P. Cresseaux ${ }^{2}$ \\ 1 Specialist certified in orthodontics and dentofacial orthopedics \\ 2 Maxillofacial surgeon
}

ABSTRACT

The difficulty of management of a transverse maxillary hypoplasia is to choose the right treatment and the appropriate tools.

When transverse maxillary insufficient is associated to sagittal and/or vertical discrepancies in adults, the gold standard treatment is a surgical procedure combined with orthodontic treatment. The surgical procedure can be done in 1 or 2 stages.

If the patient chooses a lingual orthodontic technique, the tools for expansion and the stabilization of expansion are not simple to use.

The aim of this article is to report the case of a 25-year-old male patient, referred to our cabinet for skeletal Class-III malocclusion associated with laterognathism and transverse maxillary deficiency. The patient underwent one-stage surgery. He choose to be treated by a lingual orthodontic technique, we used the $F K S^{\circledast}$ disjunction device.

\section{KEYWORDS}

Maxillary transverse hypoplasia, SARME, disjunction, lingual orthodontics, FKS ${ }^{\oplus}$ disjunction

Transverse deficiency is a frequent dysmorphic disorder ${ }^{8,2}$. In adults, the ossification of the interpalatine suture precludes the use of orthopedic devices $^{9}$. The treatment of choice to restore arch width is maxillofacial surgery combined with orthodontic treatment ${ }^{3}$. The most commonly used surgical technique for maxillary expansion is surgically assisted rapid maxillary expansion (SARME) ${ }^{7}$.

Additionally, since transverse deficiencies are often associated with other sagittal and vertical dysmorphisms, the use of bimaxillary orthodontic surgical treatment becomes essential. For stability reasons, some practitioners prefer to perform two procedures: the first to correct the transverse alignment, the second to correct the vertical and sagittal dimensions. The disadvantage of this technique is that patients are required to have two operations, both of which have inherent risks and possible recovery difficulties. We believe, like Leyder ${ }^{4,5}$, that a single procedure, which corrects the three dimensions in a single

Address for correspondence:

Chloé Bernard-Granger - 4 allée du Champ de Maïs - 74940

Annecy-Le-Vieux

E-mail: dr.bernardgranger@gmail.com

Article received: $19-11-2017$. Accepted for publication: 14-02-2018.

This is an Open Access article distributed under the terms of the Creative Commons Attribution License (http://creativecommons.org/licenses/by/4.0), which permits unrestricted use, distribution, and reproduction in any medium, provided the original work is properly cited. 
stage, is a preferable solution. Such a procedure is just as stable with much less inconvenience to the patient.

The aims of this article are to introduce the lingual disjunction device

\section{CLINICAL CASE}

We present the case of a 25-yearold young man. The patient requested that his facial asymmetry be corrected as well as his prognathism. He had already been treated in adolescence (we have no clinical records from that period), but condylar growth resumed after his initial treatment.

On extraoral examination, the patient has marked facial asymmetry with left chin deviation. The smile is asymmetrical. In profile view, an open nasolabial angle is observed, as well as prognathism and an increase in the height of the lower face.

On intraoral examination, the maxillary arch is lyre-shaped and narrow. The made by FKS ${ }^{\circledR}$ Global Orthodontic Solutions and to demonstrate the results obtained on a hyperdivergent Class-III malocclusion, treated by a single phase orthodontic surgical technique.

mandibular arch has an elliptical shape but there is zero crowding. Examining the interarches revealed transverse deficiency with inverted occlusion on the left, as well as a marked deviation of the lower median. The patient presents with a significant end-to-end incisal malocclusion (Fig. 2).

The orthopantomogram confirms the patient's good oral health, all the third molars had been removed several years previously (Fig. 3).

Profile teleradiography confirms a skeletal Class-III malocclusion of mixed origin, brachymaxilla, left hypercondylia, and facial hyperdivergence (Fig. 4).

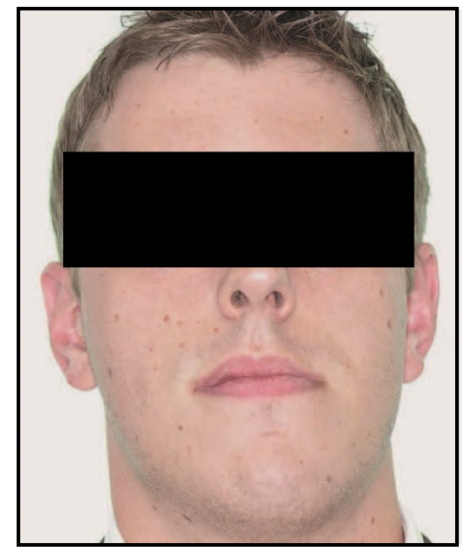

a

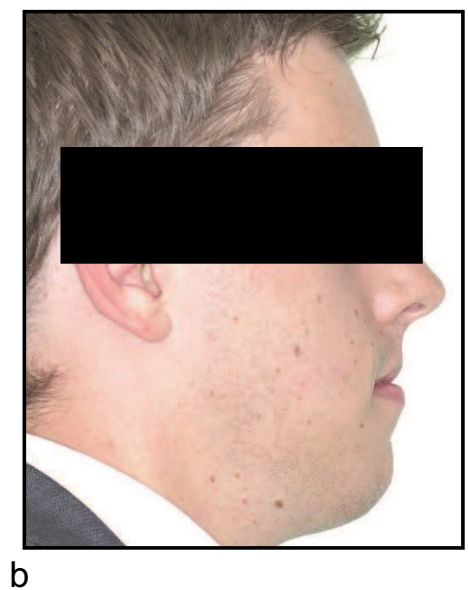

Figure 1

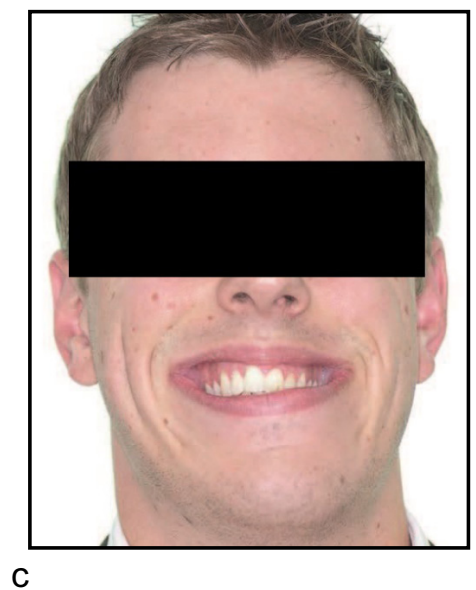

C

(a) Extraoral examination before treatment (front); (b) Extraoral examination before treatment (profile); c) Extraoral examination before treatment of the face and smile. 

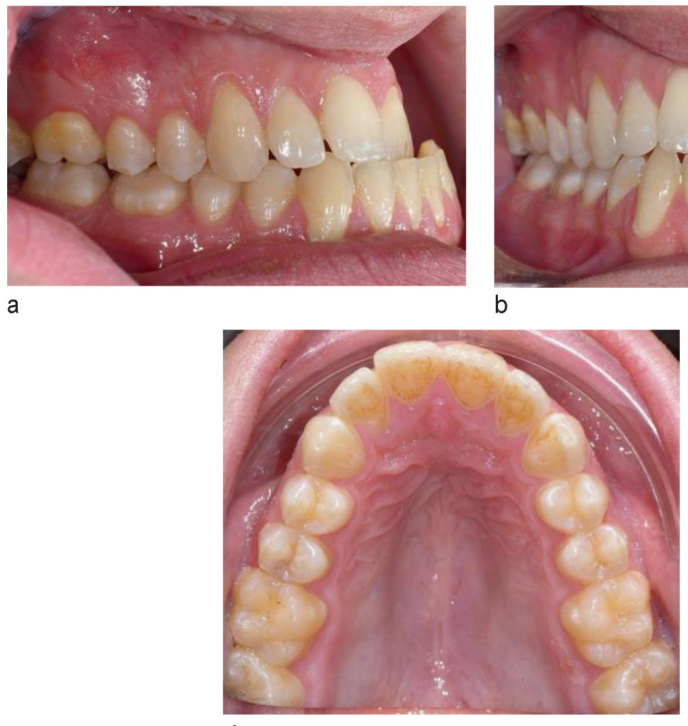

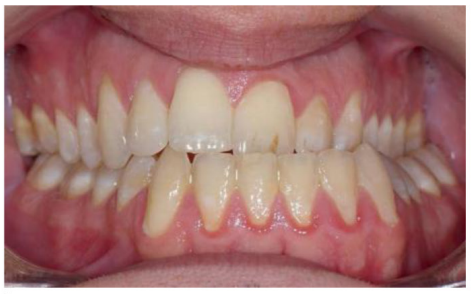

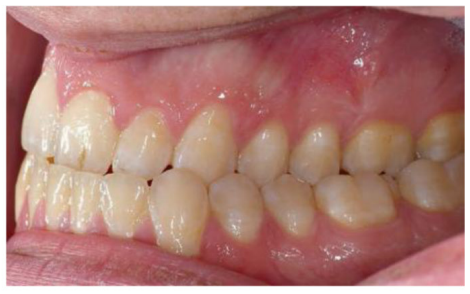

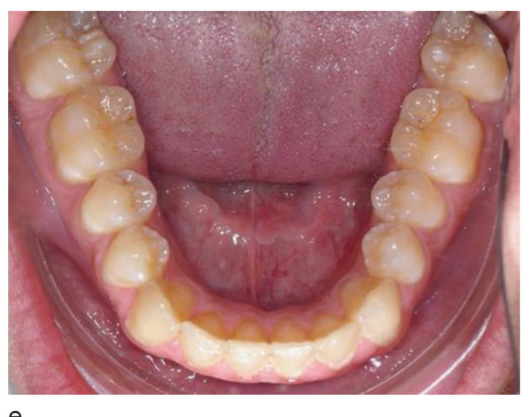

Figure 2

(a) Intraoral examination before treatment (right lateral view); (b) intraoral examination before treatment (frontal view, clenched teeth); (c) intraoral examination before treatment (left lateral view); (d) intraoral examination before treatment (occlusal view of the upper arch); (e) intraoral examination before treatment (occlusal view of lower arch).

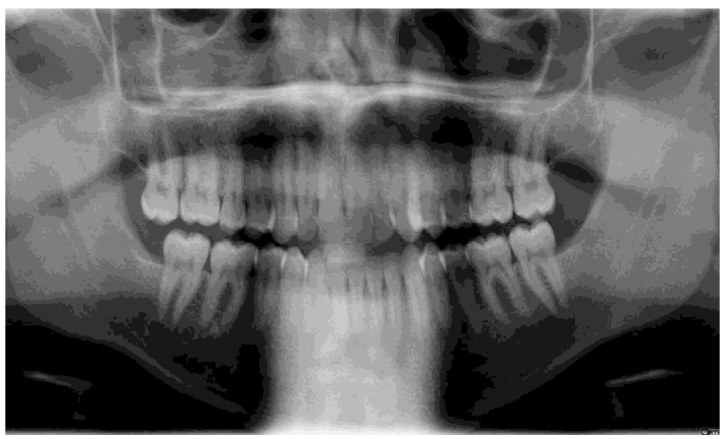

Figure 3

Initial orthopantomogram

We proposed an orthodontic surgical treatment plan. A bimaxillary osteotomy was planned with expansion, advance, and horizontalization of the maxillae and recentering of the mandible (retraction on the right and advancement on the left).

The patient wishes to be fitted with a mixed multiattachment device-i.e.,

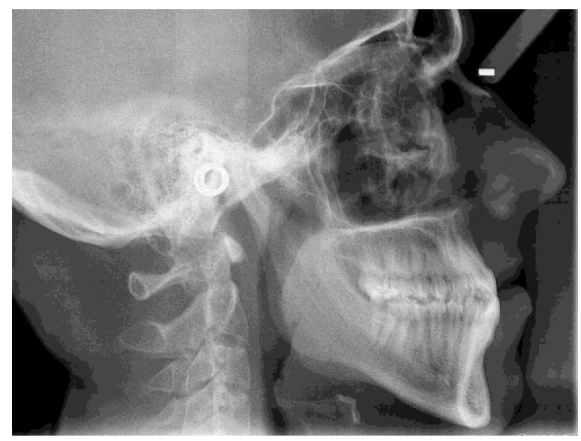

Figure 4

Initial profile teleradiography.

a mixture of attachments from the tongue to the maxilla and the vestibule to the mandible-because he expressed the desire for a comfortable and invisible device. Digitized study molds were made (Fig. 5). Impressions were taken to build the patient's orthodontic setup model. The FKS ${ }^{\circledR}$ laboratory proposed a maxillary and mandib- 

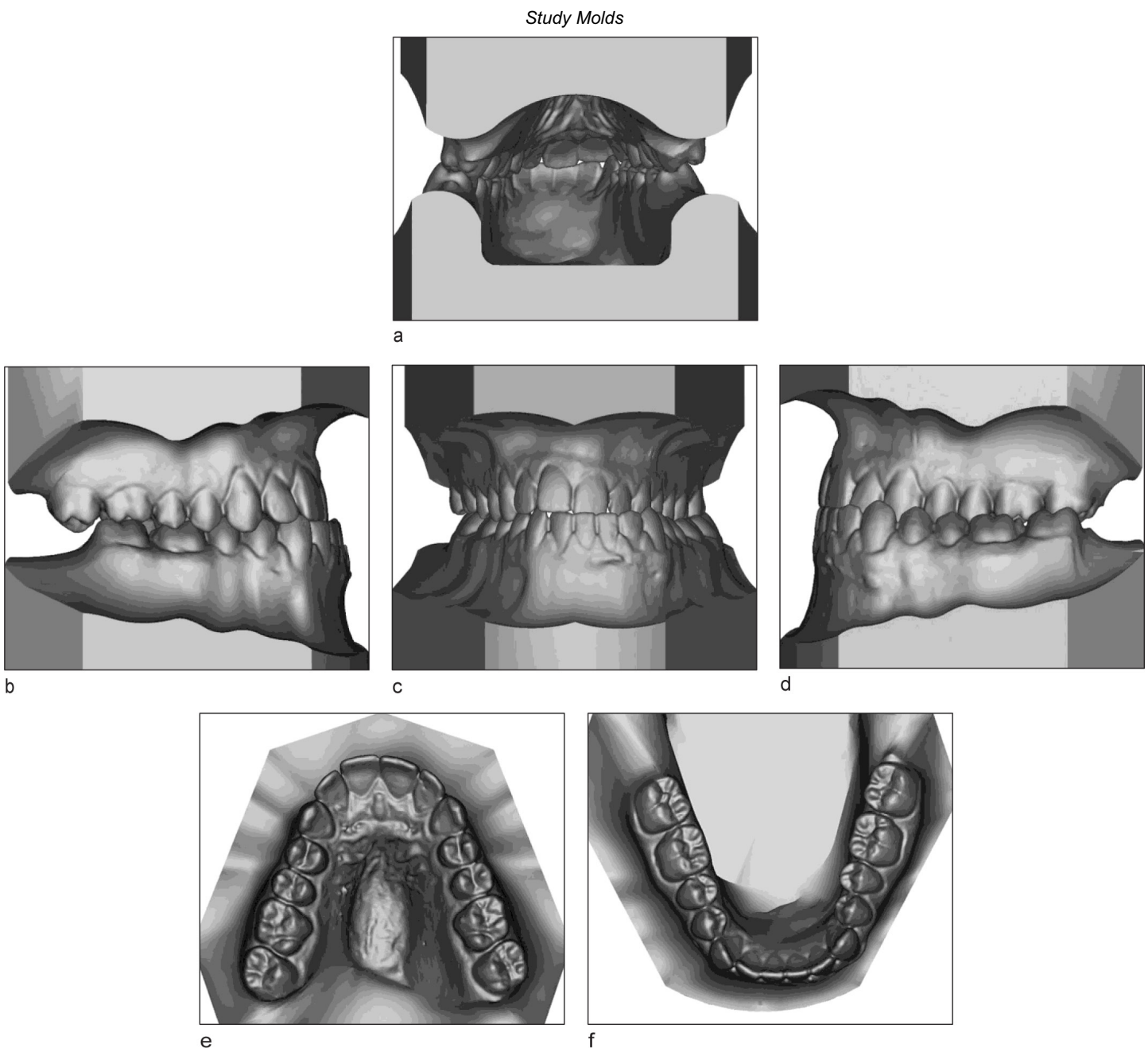

Figure 5

(a) digitized study molds (posterior view); (b) digitized study molds (right lateral view);

(c) digitized study molds (frontal view); (d) digitized study molds (left lateral view); (e) digitized study molds (occlusal view of upper arch); (f) digitized study molds (occlusal view of lower arch).

ular treatment plan to the orthodontist Dr. Filippi, who approved it (Fig. 6).

The patient was fitted with two shape-memory alloy archwires are placed during the initial session (Bio Edge $17^{\prime \prime} \times 17^{\prime \prime}$ fixed to the maxilla and $20^{\prime \prime} \times 20^{\prime \prime}$ fixed to the mandible) (Fig. 7).

Three months after placement of the multiattachment device, more rigid titanium-molybdenum alloy archwires were placed. The wire cross-section measuring $0.0175^{\prime \prime} \times 0.0175^{\prime \prime}$ were fixed to the maxilla, whereas those measuring $0.019 " \times 0.025$ " were fixed to the mandible. These archwires will be retained for the surgical stage.

One month before the date set for the operation, impressions were made to assist in constructing the disjunction device that was to be placed on the lingual arch (Fig. 8). 
Therapeutic plan (patient's setup)

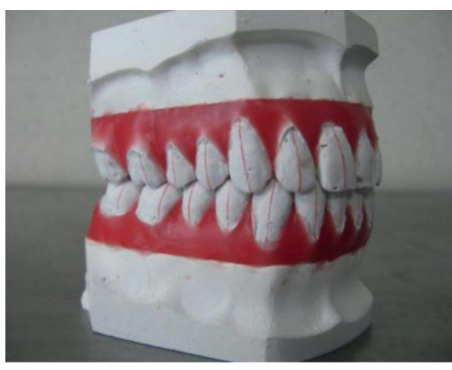

a

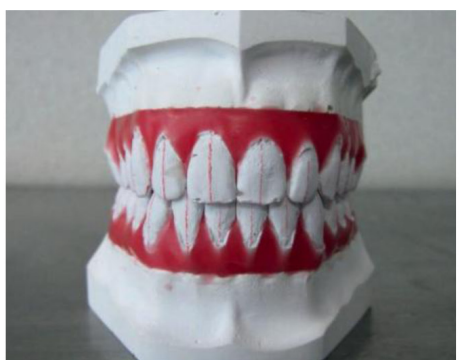

b

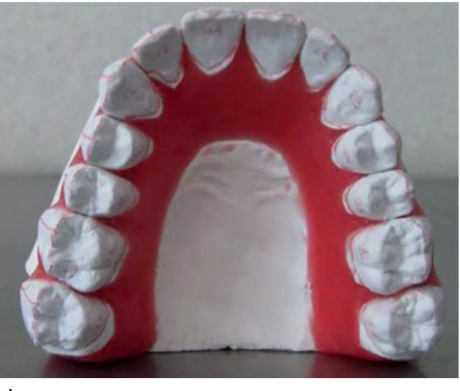

d

e

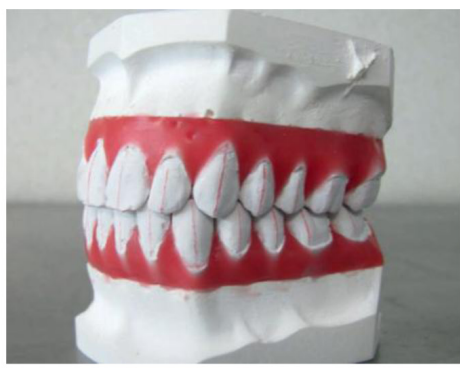

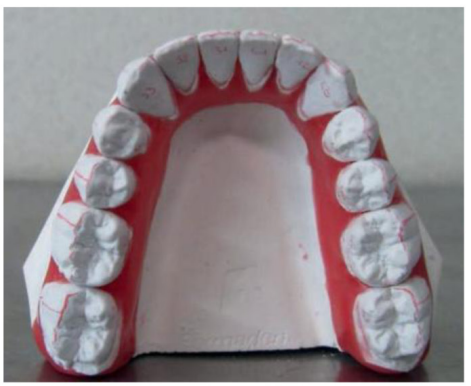

Figure 6

(a) Right lateral view; (b) Frontal view; (c) Left lateral view; (d) Upper arch view;

(e) Lower arch view.

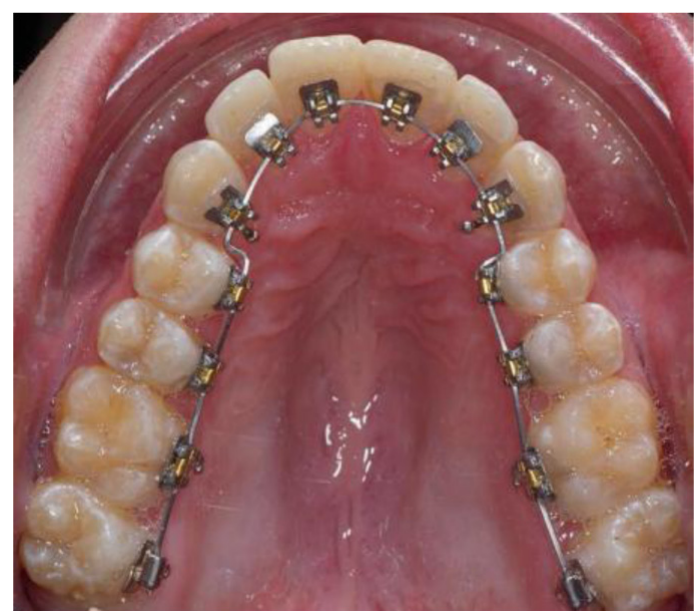

Figure 7

Patient fitted, occlusal view of the maxillary arch, lingual multiattachment with a shapememory archwire

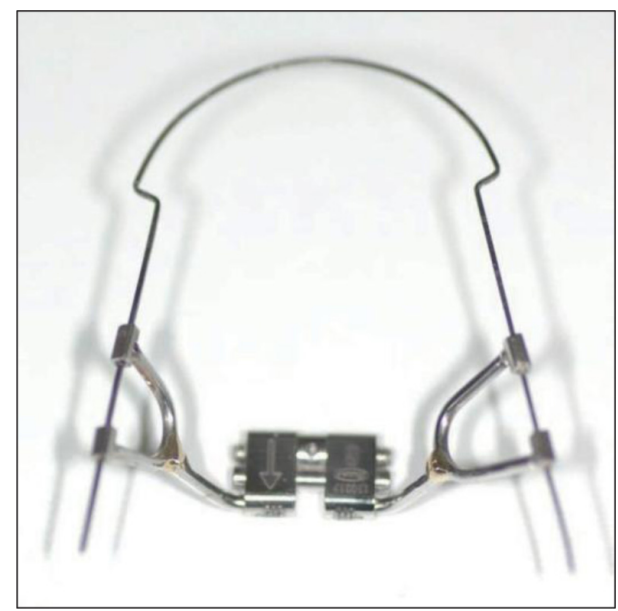

Figure 8

FKS巴 lingual disjunction device placed on the titanium-molybdenum alloy archwire. 
The disjunctor was placed a few days before the operation, during the same stage, surgical hooks were placed on the mandibular arch and ceramic braces were placed on the canines and maxillary molars. These braces were meant to allow the patient to wear interarch traction devices (Class-III devices and others with vertical components) immediately after surgery (Fig. 9).

To place the disjunctor, simply remove the orthodontic archwire, then slide the archwire into the tubes. The $\mathrm{FKS}^{\circledR}$ lingual disjunctor has two arms on either side, which are placed on both sides of tubes 16 and 26 .

In the laboratory, the $\mathrm{FKS}^{\circledR}$ lingual disjunctor was constructed slightly distal to the palate, so that it can be refitted after the intraoperative reshaping of the palatal vault.
The preoperative orthodontic phase, which lasted 10 months, made it possible to align and level the dental arches and adjusting the axes of sector 3 .

During surgery, Dr. Cresseux (maxillofacial surgeon), performed a bimaxillary osteotomy with expansion, advancement, and horizontalization of the maxilla, in addition to mandibular recentering (retraction on the right, advancement on the left). The actuator is activated intraoperatively with a 26 1/4 turn, which results in a 6-mm disjunction.

The patient is seen again 3 weeks after surgery. Intraoral photographs were taken at 3 months postoperatively (Fig. 10). The anterior vertical elastic bands were maintained by the patient. The FKS ${ }^{\circledR}$ lingual disjunctor was removed 4 months after surgery.

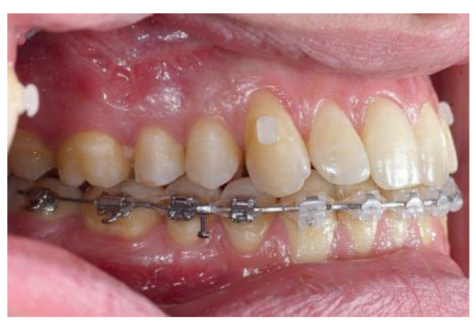

a

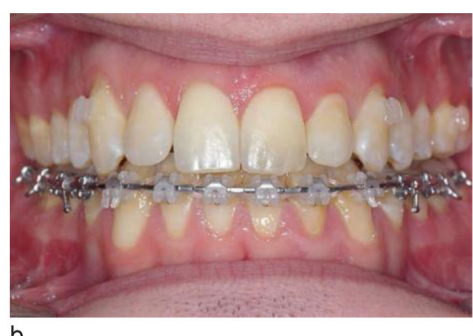

b

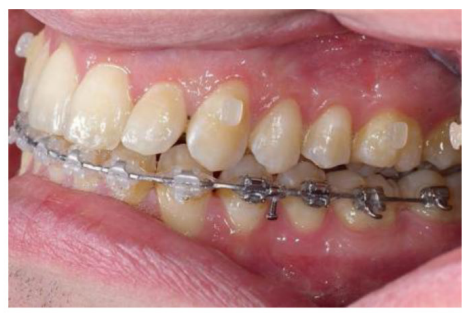

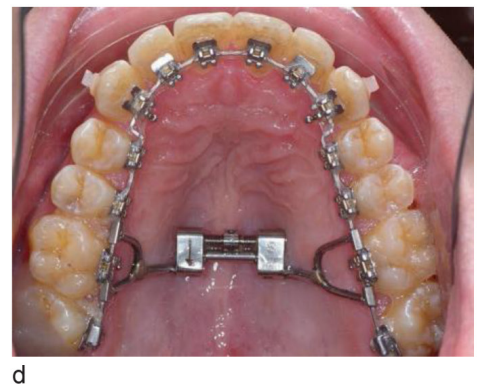

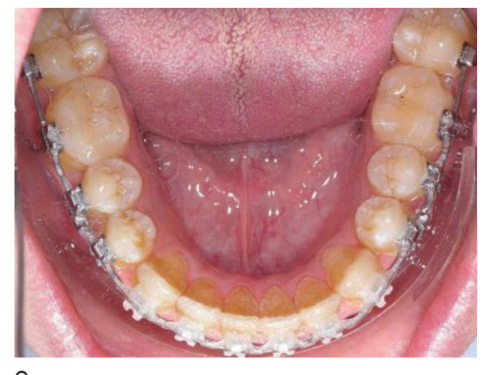

Figure 9

(a) preoperative intraoral examination (right lateral view); (b) preoperative intraoral examination (frontal view, clenched teeth); (c) preoperative intraoral examination (left lateral view);

(d) preoperative intraoral examination (occlusal view of upper arch); (e) preoperative intraoral examination (occlusal view of lower arch). 
Postoperative Photographs (at 3 months postoperatively)

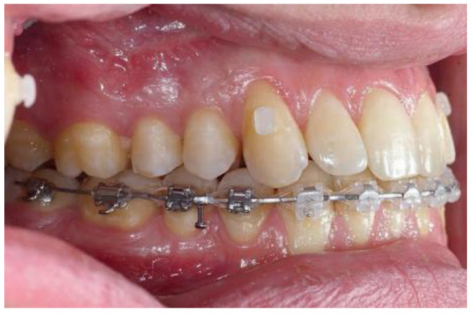

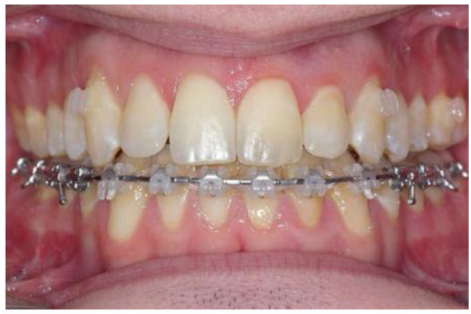

b

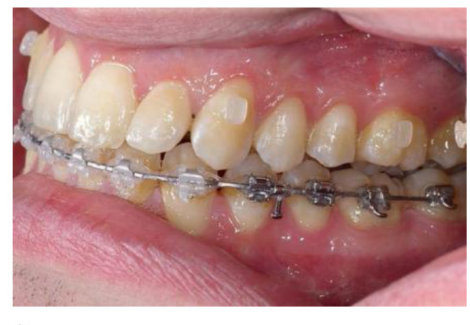

C

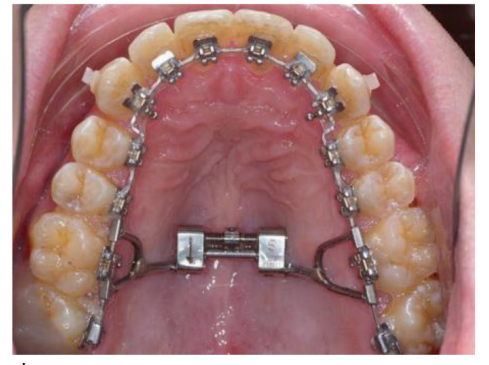

d

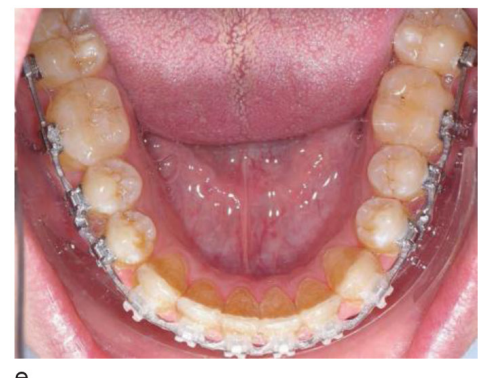

e

Figure 10

(a) postoperative intraoral examination (right lateral view); (b) postoperative intraoral examination (frontal view, clenched teeth); (c) postoperative intraoral examination (left lateral view);

(d) postoperative intraoral examination (occlusal view of the upper arch); (e) postoperative intraoral examination (occlusal view of the lower arch).

Orthodontic finishing was performed and the multiattachment device was removed 10 months after the surgery, for a total treatment duration of 20 months.

On the day of its removal, a retainer bonded from canine to canine was placed on the mandible and a custom maxillary splint was given to the patient.

To date, the patient has not requested the removal of the osteosynthesis plates.

\section{RESULTS}

End-of-treatment photographs were taken 3 months after the removal of the multiattachment device and the placement of retainers (Fig. 11).

Extraorally, a very satisfying esthetic result was observed. Facial symmetry was restored, the smile was full, and there was no visible black lateral corridor.
Intraorally, the transverse deficiency was corrected. The midlines were aligned, and the non-vertical versions of the teeth were straightened. A dental class-I malocclusion was acquired on both the right and left sides and the overlap was straightened (Fig. 12, 13). 
Postoperative extraoral photographs (3 months after retainer placement)

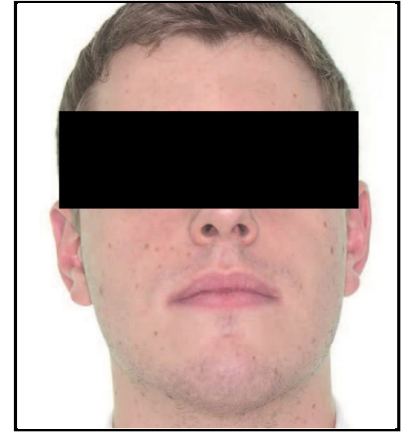

a

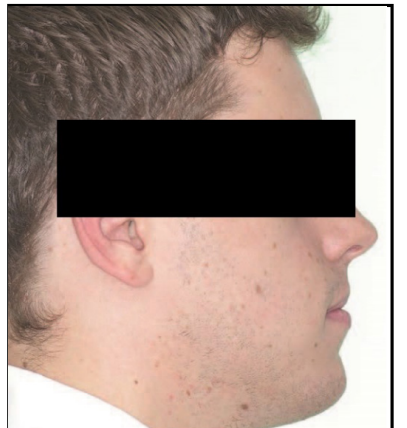

b

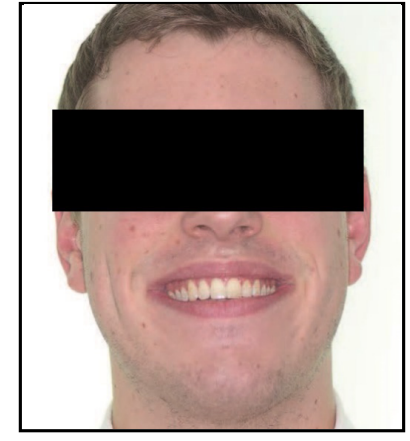

C

Figure 11

(a) extraoral frontal photograph; (b) extraoral profile photograph; (c) extraoral frontal photograph of patient's smile.

Postoperative intraoral photographs (3 months after retainer placement)

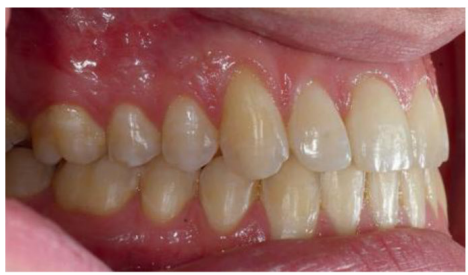

a

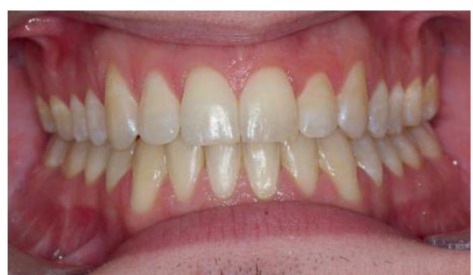

b

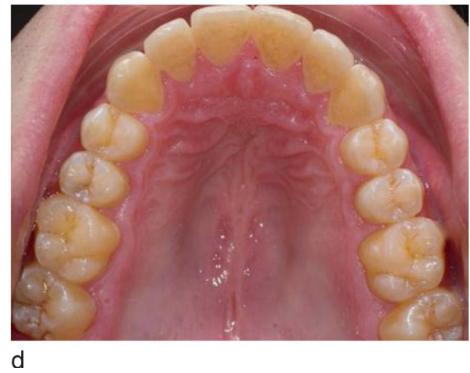

d
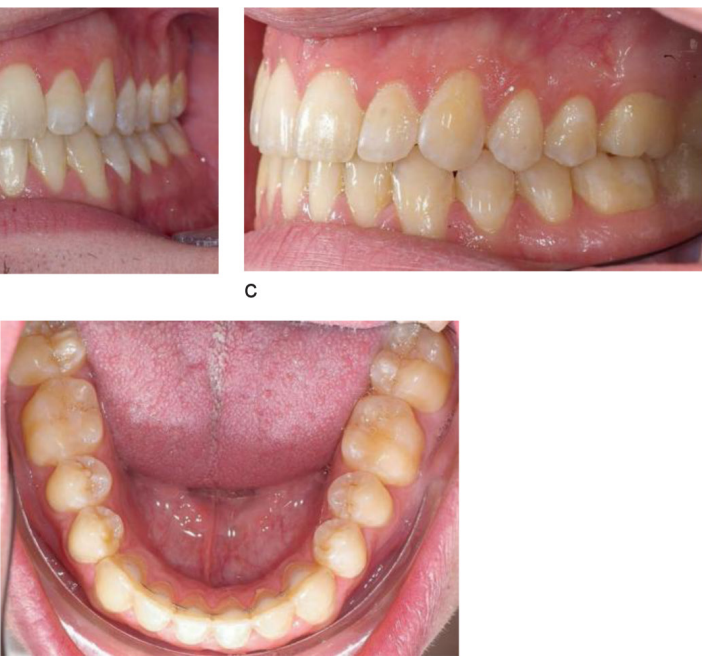

e

Figure 12

(a) End-of-treatment intraoral examination (right lateral view); (b) End-of-treatment intraoral examination (frontal view, clenched teeth); (c) End-of-treatment intraoral examination (left lateral view); (d) End-of-treatment intraoral examination (occlusal view of upper arch); (e) End-of-treatment intraoral examination (occlusal view of lower arch). 


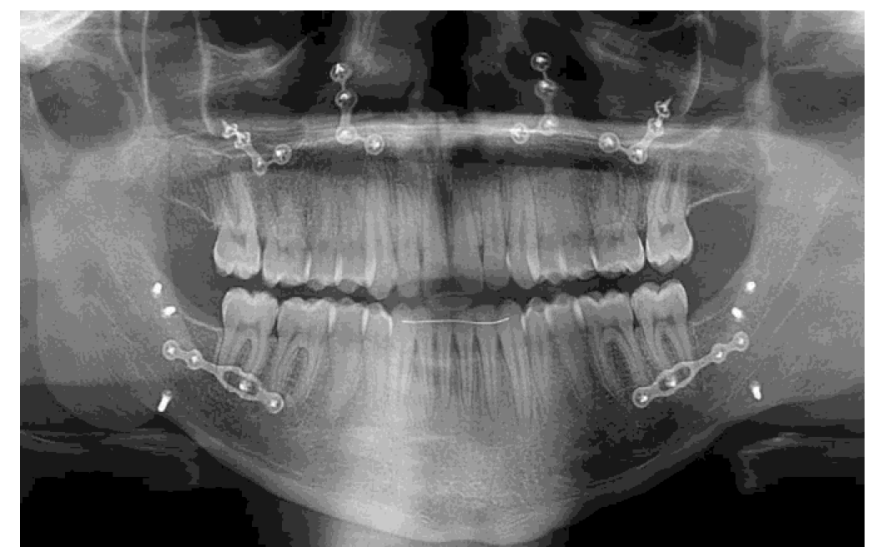

Figure 13

Postoperative orthopantomogram.

\section{DISCUSSION}

\section{Lingual Disjunctor}

The lingual disjunctor is part of the $\mathrm{FKS}^{\circledR}$ system. It can be adapted to any type of lingual multiattachment device. Two tube choices are available: $0.022^{\prime \prime} \times 0.028^{\prime \prime}$ or $0.018^{\prime \prime} \times 0.025$ ". Two types of actuators are also available, depending on the amount of disjunction desired: $8 \mathrm{~mm}$ or $11 \mathrm{~mm}$. The device is made in France (Fig. 14).

This system improves the practitioner's ergonomics and the patient's comfort. The difficulty experienced with lingual maxillary expansion is because of the fact that the lingual attachments and expansion device are situated on the same side. In 2014', Galetti and Deffrennes recommended a tooth-supported removable expansion device, but this very practical system can only be used with vestibular attachments.

The solutions attained using the lingual attachment are as follows: the removal of the 16 and 26 lingual attachments. This is followed by the placement of a standard disjunctor and transpalatal arches and a maxillary disjunction directly on a bone-supported device ${ }^{9}$.

The appeal of the $\mathrm{FKS}^{\circledR}$ lingual disjunctor is that it is able to pass the force vector of the disjunctor through the center of the bracket base to prevent debonding of the attachment. Moreover, of the 64 cases treated by this technique in orthodontic offices, there have not been any instances of lingual attachment debonding at 16 or 26 after using this system.

The FKS ${ }^{\circledR}$ disjunctor makes it possible to overcome the difficulties encountered with other systems. For example, mandatory patient cooperation with wearing the palatal plate (if a vestibular multiattachment technique is used) is not required. Second, having the laboratory create a transpalatal arch may prove difficult to regulate with additional inconvenience for the patient, as well as increased costs and operating time to install bone anchorages. 


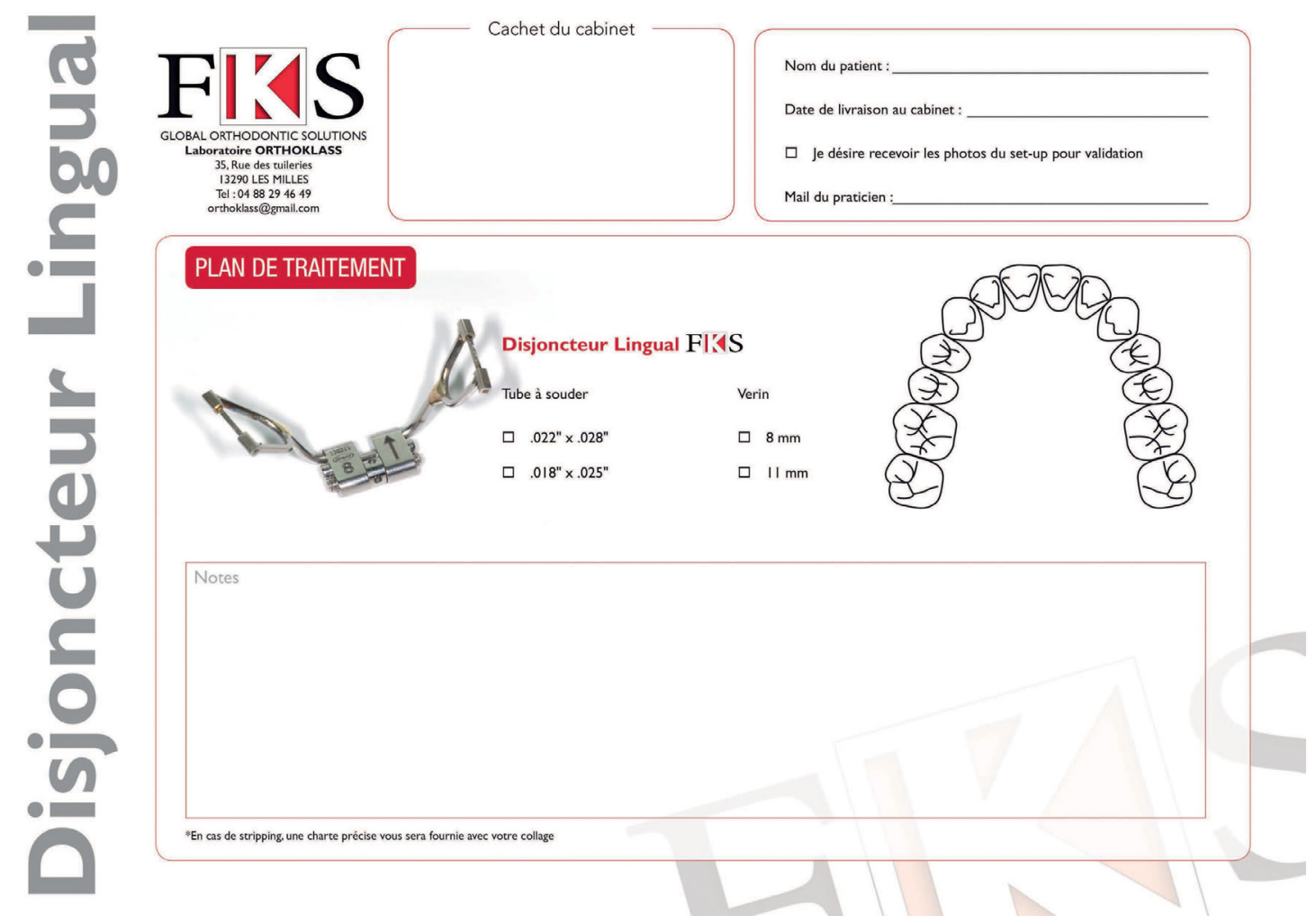

Figure 14

Order form for lingual disjunctor.

This system is comfortable for the patient. Its placement is relatively easy for the both the practitioner and the patient (no orthodontic braces, no pain on insertion, protection of the periodontium), and its removal is also

\section{Single-stage surgical intervention}

The management of the transverse dimension is frequently neglected when compared to the vertical or sagittal dimensions. Correcting transverse maxillary hypoplasia widens the maxillary apical base and the palatal vault, which gives more space to the tongue and decreases the risk of recurrence ${ }^{5}$. Rehabilitation and standardization of functions are thus facilitated. simple. Once activated, it maintains the amount of disjunction while allowing the lingual device to continue its dental movements. The maintenance of the disjunctor is easy for the patient.

The effective management of this direction is essential during orthodontic surgical treatment to obtain the best possible result. Moreover, if well-managed, we believe that this type of correction remains stable even if it is processed during the bimaxillary operation.

Management of the transverse direction should not automatically require exclusive transverse treatment in the 
initial surgical stage. The important thing is that the postoperative, lateral covering is sufficient so that occlusion and natural mastication maintain the results obtained intraoperatively.

In our example, the disjunctor is removed 4 months after the surgery because the occlusion effectively maintains the maxillary expansion. This usually results in an effective functional rehabilitation.

\section{CONCLUSION}

Surgeries in the transverse dimension have triggered a great debate. Long ignored, they are now considered a key contributor to the success of orthodontic surgical treatments.

The disjunction is often performed during the initial surgical stage. However, our personal experience shows that excellent results are obtained when all three directions are managed in a single stage. The determining factor for the final stability seems to be the occlusion obtained immediately after surgery.
A year and a half after the removal of the device, the stability of the transverse dimension for this patient is excellent.

On the other hand, a single surgical procedure is a real comfort for the patient. The stress generated is decreased, as are the after-effects and postoperative discomforts. Rehabilitation can be performed at once and the faster recovery means decreased absenteeism from work.

The lingual disjunctor presented in this study represents a significant advancement in the treatment and management of surgical cases treated by lingual orthodontics. The ease of use, comfort, and ergonomics that it provides are truly advantageous to both the practitioner and the patient.

Conflict of interest: The authors declare having no conflict of interest. The author Raphaël Filippi is the system developer at the FKS laboratory.

\section{BIBLIOGRAPHY}

1. Galletti C, Deffrennes D. One-step surgery and correction of the transverse dimension of the maxilla using the lingual technique: an original assisted transverse surgery method. Int Orthod 2014;12(3):345-357.

2. Haute autorité de santé. Service d'évaluation des actes professionnels. Bilan de dysmorphose dento-maxillo- faciale. 2006.

3. Koudstaal MJ, Poort LJ, van der Wal KGH, Wolvius EB, Prahl-Andersen B, Schulten AJM. Surgically assisted rapid maxillary expansion (SARME): a review of the literature. Int J Oral Maxillofac Surg 2005;34(7): 709-714.

4. Leyder P, Wycisk G, Quilichini J. [Sliding osteosynthe- sis: a new technique for transverse palatal distraction osteogenesis associated with advancement and/or impaction Le Fort I osteotomy]. Rev Stomatol Chir Maxillofac Chir Orale 2013;114(1):19-23. 
5. Leyder P, Altounian G, Chardain J, Quilichini J. Adjustable selective maxillary expansion combined with maxillomandibular surgery: A case report. Int Orthod 2015;13(3):320-331.

6. Marinetti A, Taboulet JM, Deffrennes D. Disjonction maxillaire chirurgicale à l'aide d'un distracteur à appui osseux. Inf Dent 2009;(15).

7. Menon S, Manerikar R, Sinha R. Surgical management of transverse maxillary deficiency in adults. J Maxillofac Oral Surg 2010;9(3):241-246.

8. Patti A. Traitement des classes II. De la prévention à la chirurgie. Quintessence International, 2010.

9. Salgueiro DG, Rodrigues VHL de O, Tieghi Neto V, Menezes CC de, Gonçales ES, Ferreira Júnior O. Evaluation of opening pattern and bone neoformation at median palatal suture area in patients submitted to surgically assisted rapid maxillary expansion (SARME) through cone beam computed tomography. J Appl Oral Sci Rev FOB 2015;23(4):397-404. 